\title{
Diagnosis of Encephalitic Listerial Outbreak in Sheep-Immuno-Histopathological Study
}

\author{
Vishal Mahajan ${ }^{*}$, Mandeep Singh Bal ${ }^{1}$, Gursimran Filia ${ }^{1}$, \\ Geeta Devi Leishangthem ${ }^{2}$ and Kulbir Singh Sandhu ${ }^{1}$
}

${ }^{1}$ Animal Disease Research Centre, ${ }^{2}$ Department of Veterinary Pathology, Guru Angad Dev Veterinary and Animal Sciences University, Ludhiana, Punjab-141004, India

*Corresponding author

\section{A B S T R A C T}

Keywords

Immunohistochemis try, Outbreak,

Listeriosis, Small

ruminants

Article Info

Accepted:

21 May 2020

Available Online:

10 June 2020
Listeriosis caused by Listeria monocytogenes is an infectious and zoonotic disease affecting wide range of animals including ruminants. An outbreak of listeriosis was investigated in migratory flock of sheep and goat in Punjab. Outbreak of encephalitic listeriosis in sheep was diagnosed by characteristic clinical signs, histopathology and confirmed by Immunohistochemistry (IHC). Microscopically, there were multifocal areas of aggregation of neutrophils forming microabscesses a pathognomic lesion of the disease. Confirmation of the outbreak was done by IHC which showed positive immunoreactivity to anti- listeria polyclonal antibody in brain stem.

\section{Introduction}

Listeriosis caused by Listeria monocytogenes is an OIE enlisted infectious disease affecting ruminants, monogastric animals and man. The infection is usually manifested by three distinct non-overlapping clinical syndromes, namely: meningoencephalitis, septicaemia and abortions ${ }^{1}$. Encephalitic listeriosis is more prevalent among ruminants, especially sheep. Encephalitic form resulting from abrasions of the buccal mucosa most likely follows an ascending infection along trigeminal nerve to the brain stem ${ }^{2,3}$. Meningoencephalitis caused by listeria produces characteristic lesions of micro-abscesses in the brain stem. The disease has been reported in small ruminants in an outbreak form in Punjab ${ }^{4,5}$. The present paper reports the outbreaks of listeriosis in migratory flock of sheep and goat in Punjab and describes the clinical features, histopathological changes and confirmation by immunohistochemistry. 


\section{Materials and Methods}

An outbreak of Listeioisis was attended and investigated in Punjab state affecting migratory flock of sheep and goat. Clinical examination of the sheep and goats were carried out and temperature, pulse rate and respiratory rate were recorded. Blood samples were collected and analyzed for complete hematology. CSF from affected sheep was also collected. A detailed Post-mortem examination of the dead sheep was conducted following routine procedures. Tissue samples from the brain stem viz. medulla oblongata, pons, cerebellum were collected in 10\% neutral buffered formalin for routine histopathology and stained with haematoxylin and eosin (H\&E) as per standard protocol ${ }^{6}$. Immuno-histochemical staining was performed by using advanced $\mathrm{SS}^{\mathrm{TM}}$ One-Step Polymer-HRP IHC Detection System (BioGenex Laboratories Inc., San Ramon, California, USA) as per manufacturer's instructions. A polyclonal antibody against Listeria monocytogenes (ABD Serotac) was used in a dilution of 1:500. As negative control, sections were incubated with PBS instead of the primary antibody.

\section{Results and Discussion}

An outbreak of listeriosis was investigated in migratory flock of sheep and goat in Punjab during the month of December, 2019. Out of 90 sheep and 16 goats at risk, 22 sheep were critically ill and 16 sheep died of disease with morbidity, mortality and case fatality rate of 20.7, 15.1 and $72.7 \%$ respectively. Clinical examination of affected sheep showed high fever $\left(106^{\circ} \mathrm{F}\right)$, circling movement, unilateral blindness, facial paralysis with hanging of jaw and drooling of saliva from mouth, dropping of tongue, indicative of nervous involvement. At the time of death sheep was recumbent, showed convulsions and paddling movements. All the 16 goats did not show any clinical sign of the disease. CSF collected from affected sheep was cloudy and cytological examination revealed increase in number of cells particularly neutrophils indicative of pleocytosis. Postmortem examination of dead sheep revealed no specific lesion in internal organs except congestion of meninges was noted. Hitopathological examination revealed multifocal areas of aggregation of neutrophils forming micro-abscesses (Fig. 1) in brain stem. Moreover, perivascular lymphocytic cuffing (Fig. 2) in the Virchow robin space in the brain stem was also seen. Immunohistochemical examination revealed positive immunoreactivity to anti listeria polyclonal antibody particularly intracellular in neutrophil and macrophages in abscess (Fig. 3).

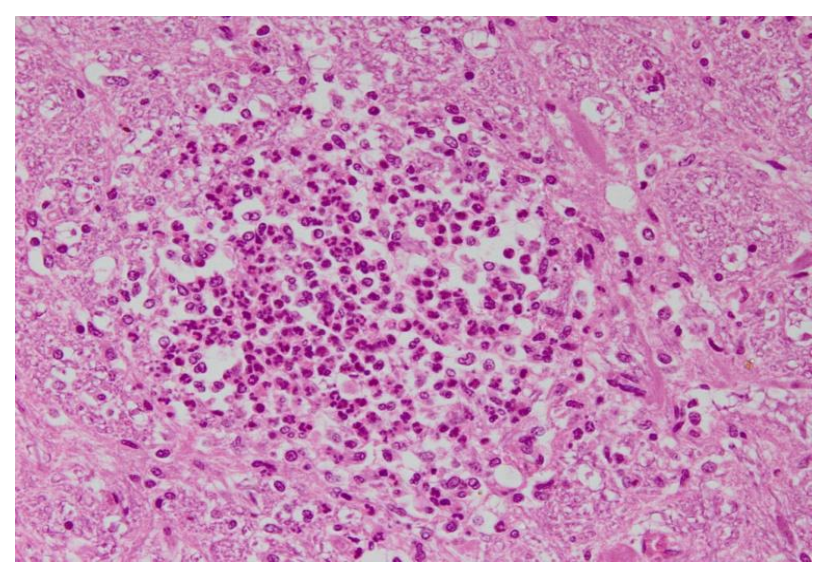

Figure.1 Photomicrograph of brain stem with microabscess (H\&E, 20X) 


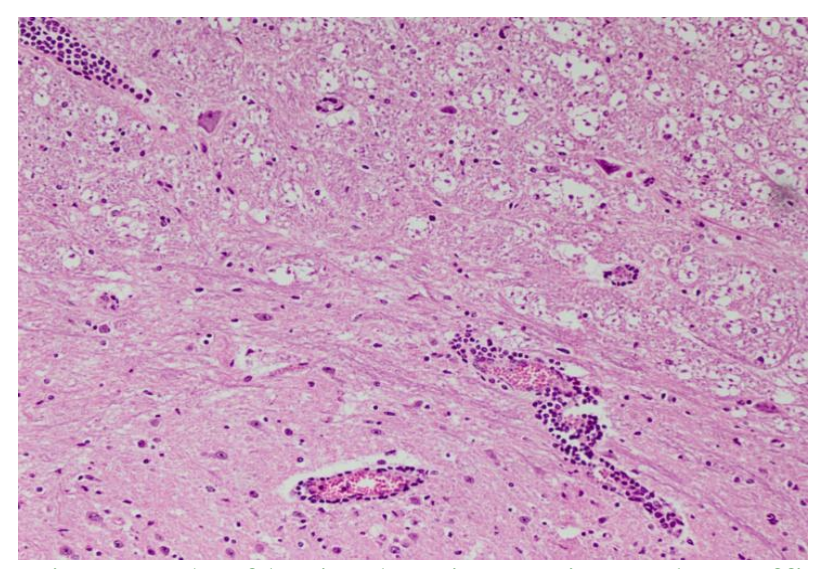

Figure.2 Photomicrograph of brain showing perivascular cuffing (H\&E, 20X)

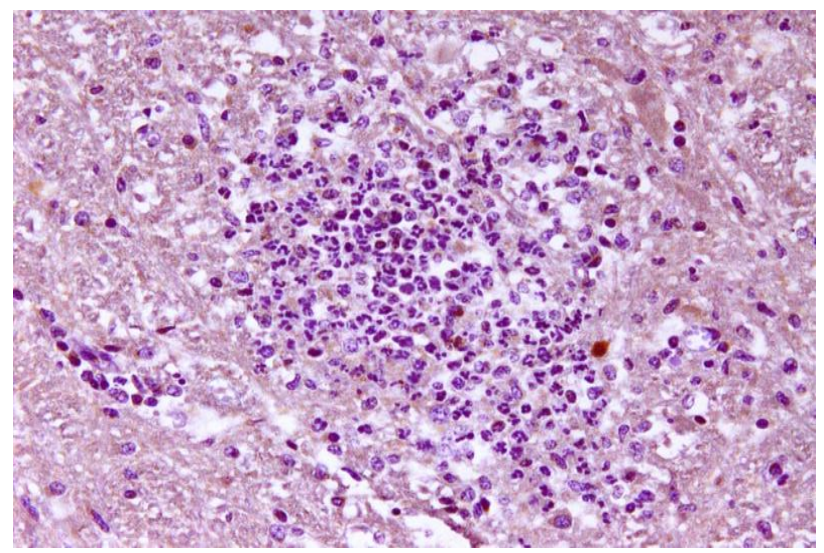

Figure.3 Positive immunoreactivity to anti-listeria polyclonal antibody in abscess (IHC, 40X)

Listeriosis is an important public health problem worldwide and can cause abortion, encephalitis and septicemia in ruminants ${ }^{1}$. An outbreak was reported in migratory flock of sheep in month of December. Since during winter months temperature is favourable for growth of bacteria as listeria survive better in cold condition resulted in outbreak of listeriosis as reported earlier ${ }^{4}$. In the present study none of the goat was affected with disease. This might be difference in their feeding habits of grazing and browsing in sheep and goat respectively. The encephalitic form mainly results from injured oral mucosa with stumps of grasses during grazing in winter months followed by ascending of bacteria from trigeminal nerve to brain ${ }^{4,5}$. Clinical signs of nervous involvement were similar to earlier studies ${ }^{4,5}$.
Meningoencephalitis characterized by microabscesses, perivascular cuffing, satellitosis and neuronophagia observed at histological examination in the present outbreak of listeriosis were in agreement with those described in literature ${ }^{4,5,7}$.

IHC is sensitive and specific technique for diagnosis of infectious agents in formalin fixed tissue samples ${ }^{8}$.In the present study, positive immunoreactivity of listeria in microabscesses of brain stem as was reported previously $^{1,9,10}$.

Thus, present study revealed IHC supplemented with histopathology is a rapid and specific technique for confirmation of natural cases of $L$. monocytogenes encephalitis on formalin-fixed specimens from small ruminants. 
Conflict of interest: No conflict of interest

\section{References}

1. Haligur M, Aydogan A, Ozmen $\mathrm{O}$ and IpekV. 2019. Immunohistochemical evaluation of natural cases of encephalitic listeriosis in sheep. Biotechnic \& Histochemistry 94(5): 341-47

2. Jubb KVF and Huxtable CR. 1993: The nervous system. In: Jubb K. V.F., P. C. Kennedy, N. Palmer (eds), Pathology of Domestic Animals, 4th edn, pp. 393-397. Academic Press, San Diego, CA, USA.

3. Rebhun WC. 1987. Listeriosis. Veterinary Clinics of North America: Food Animal. Practice, 3: 75-83.

4. Kumar H, Singh BB, Bal MS, Singh R, Kaur K, Sidhu PK and Sandhu KS. 2007.Pathological and epidemiological investigation into listerial encephalitis in sheep. Small ruminant Research, 71: 29397.

5. Mahajan V, Sharma S, Filia G and Banga HS (2010). Listerial Encephalitis outbreak in sheep: A Clinico-Pathological and microbiological study. Indian Veterinary Journal. 87(8)

6. Luna LG. 1968. Manual of Histologic
Staining Methods of the Armed Forces Institute of Pathology. Third Edition McGraw-Hill Book Company, New York.

7. Krueger N, Low $\mathrm{C}$ and Donachie W. 1995. Phenotypic characterization of the cells of the inflammatory response in ovine encephalitic listeriosis. Journal of Comparative Pathology 113: 263-75.

8. Haines, D. M., and B. J. Chelack, 1991: Technical considerations for developing enzyme immunohistochemical staining procedures on formalin-fixed paraffinembedded tissues for diagnostic pathology. Journal of Veterinary Diagnostic investigation, 3: 101-12.

9. Weinstock D, Horton SB and Rowland PH. 1995: Rapid diagnosis of Listeria monocytogenes by immunohistochemistry in formalin-fixed brain tissue. Veterinary Pathology, 32:193-95.

10. Campero CM, Odeón AC, Cipolla AL, Moore DP, Poso MA and Odriozola E. 2002. Demonstration of Listeria monocytogenes by immunohistochemistry in formalin-fixed brain tissues from natural cases of ovine and bovine encephalitis. Journal of Veterinary Medicine. (B) 49: 379-83.

\section{How to cite this article:}

Vishal Mahajan, Mandeep Singh Bal, Gursimran Filia, Geeta Devi Leishangthem and Kulbir Singh Sandhu. 2020. Diagnosis of Encephalitic Listerial Outbreak in Sheep-ImmunoHistopathological Study. Int.J.Curr.Microbiol.App.Sci. 9(06): 3235-3238. doi: https://doi.org/10.20546/ijcmas.2020.906.386 